\title{
Oil Pollutants Degradation of Nano-MgO in Micro-Polluted Water
}

\author{
Meng-Fu Zhu, Cheng Deng, Hong-Bo Su, Xiu-Dong You, Lu Zhu, Ping Chen, Ying-Hai Yuan \\ Institute of Medical Equipment, Academy of Military Medical Sciences, Tianjin \\ Email: zmf323@163.com
}

Received April, 2013

\begin{abstract}
The removal of oil pollutants from water and purifying process of oil-polluted water are studied through catalytic degradation method with nano-MgO. The results indicated that catalytic degradation effect of nano-MgO on the oil pollutants was associated with dosage of nano-MgO, $\mathrm{pH}$ and water temperature. When oil content was $1.8 \mathrm{mg} / \mathrm{L}, 0.17 \mathrm{~g}$ nano-MgO was used and the removal rate of oil was 93.92\%. Furthermore, nano-Mgo was a non-photosensitive catalyst. GC/MS analysis showed that the amount of petroleum-based pollutants in water was reduced $73.77 \%$ from the previous 61 kinds to 16 kinds, and the total peak area was reduced 96.05\% after catalytic degradation of nano-MgO. Therefore, nano-MgO has an excellent effect on the catalytic degradation of oil pollutants and can be applied in the treatment of oil wastewaters.
\end{abstract}

Keywords: Nano-MgO; Oil Pollutants; Catalytic Degradation; Micro-Polluted Water; Water Treatment

\section{Introduction}

Micro-polluted water refers to that water whose physi$\mathrm{cal}$, chemical and microbial properties can't meet the demands of water quality as a source of drinking water. Generally speaking, pollutants in the micro-polluted water are often regarded as trace organics, including natural organic matter (NOM) and synthetic organic compound (SOC). Due to the accidents of oil spill and the over emission of oily sewages from industry, agriculture, transportation and daily life, the concentration of oil and its related products in our drinking water increased continuously. Thus oil pollutants have become one of the major problems toward the present water pollution. In China, Drinking Water Sanitary Standard has strictly regulated the ingredients of petroleum products [1]. Oil is comprised of hundreds of organics, mainly including alkanes, aromatic hydrocarbons and cyclones, which account for $50 \%-90 \%$ of the total oil content, and the rest are non-hydrocarbon oxygenates, sulfur or nitrogenous nitrogenous compounds [2]. The oil pollutants are considered to have adverse effects on human body and natural environment because of their high mutagenic activity, whereas nanomaterials have excellent properties of adsorption and catalytic degradation of the organic pollutants in the water, due to the small particle size, high specific surface area, high surface activity, a great numbers of surface defects and surface ions, etc $[3,4,5,6]$. In this study, self-made nano-MgO was used as the cata- lyst for the treatment of oil pollutants in micro-polluted water to investigate the catalytic degradation and contributing factors off nano-MgO.

\section{Experiment}

\subsection{Reagent and Instrument}

Carbon tetrachloride, analytically pure, ChangMao chemical regent factory (Beichen District, Tianjin); An- hydrous sodium sulfate, analytically pure, ChangMao chemical regent factory (Beichen District, Tianjin); Potassium permanganate, analytically pure, Tianjin No.1 chemical regent factory; Sodium oxalate, standard, Beijing chemical plant; Petroleum, obtained from Jilin oilfield; Nano-MgO, particle size $8.5 \mathrm{~nm}$, specific surface $163.23 \mathrm{~m}^{2} / \mathrm{g}$, thin needle-like crystal, self-made.

JDS-105U infrared spectrophotometry oil measuring instrument, BeiGuang analytic instrumental factory; 5890-5971 GC/MS, Agilent Technology.

\subsection{Experimental Method}

Crude oil was used to prepare the micro-polluted water. A certain amount of nano-MgO was added into the micro-polluted water, and then stirred uniformly. After a period of catalytic degradation reaction, the oil content in the water was measured by oil measuring instrument and the original oil content was also measured as a control before the reaction. Finally, we calculated the degrada- 
tion rate and analyzed the components through GC/MS.

\section{Result and Discussion}

\subsection{The Influence of Dosage of MgO on Oil Degradation}

Different amount of nano-MgO was added into the micro-polluted water, whose original state was $1.8 \mathrm{mg} / \mathrm{L}$ in oil content, 7 in $\mathrm{pH}$ and $20^{\circ} \mathrm{C}$ in temperature. As the reaction time went to $30 \mathrm{~min}$, we began to study the influence of the amount of nano-MgO on the oil removal. The results in Figure 1 showed that the degradation rate of oil was raised with increase of the dosage of nano$\mathrm{MgO}$. When dosage reached to $0.17 \mathrm{~g}$, the degradation rate was the most, and then it began to decrease with increase of the dosage of nano-MgO. It might be due to the fact that the increasing amount of nano-MgO caused a larger numbers of hydroxyl radicals in solution, the enhancement of oxidation ability and an increase in reactive center, thereby improving the effect of oil removal. When dosage was above $0.17 \mathrm{~g}$, nano-MgO particles were easily to aggregation, leading to less specific surface area and the decrease of oil degradation rate.

\subsection{The Influence of $\mathbf{p H}$ on the Oil Degradation}

Figure 2 showed the plot of $\mathrm{pH}$ versus oil degradation rate of nano-MgO. The reaction temperature was $20^{\circ} \mathrm{C}$ and reaction time was $30 \mathrm{~min}$. The original content of oil and dosage of $\mathrm{MgO}$ were $1.8 \mathrm{mg} / \mathrm{L}$ and $0.17 \mathrm{~g}$ respectively. We can find that the degradation rate was closely relevant to $\mathrm{pH}$, and indeed the rate was raised with the increase of $\mathrm{pH}$. This results from the fact that the solution $\mathrm{pH}$ can change the surface charge properties of nano$\mathrm{MgO}$ and the ionic composition of the organic matter in water, determine the interaction of electrostatic attraction and repulsion between catalyst surface and organics, thereby influencing the results of organic catalytic degradation.

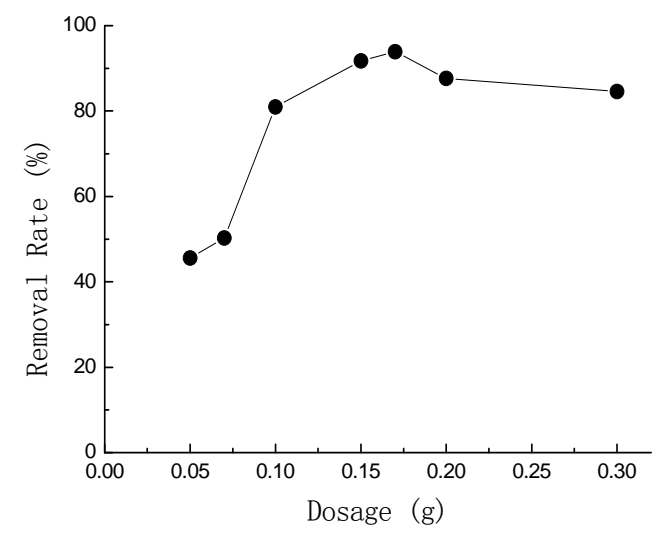

Figure 1. The influence of dosage of MgO on oil degradation.

\subsection{The Influence of Temperature on Oil Degradation}

Figure 3 showed the plot of temperature versus oil degradation rate of nano-MgO. The reaction time was 30 min. The original content of oil and dosage of $\mathrm{MgO}$ were $1.8 \mathrm{mg} / \mathrm{L}$ and $0.17 \mathrm{~g}$ respectively. With the increase of reaction temperature, the oil degradation was raised gradually. It was because that increasing the temperature can enhance the diffusion and transfer of reactant molecules or intermediates on the surface of catalyst, resulting in more chances of contact between reactant molecules and intermediates. Beyond $20^{\circ} \mathrm{C}$, however, temperature changes made little influence on oil degradation. Therefore, normal temperature was suitable for nano-MgO to catalytic degradation of oil pollutant in water.

\subsection{The Influence of Reaction Time on Oil Degradation}

Figure 4 showed the plot of reaction time versus oil degradation rate of nano-MgO. The reaction temperature was $20^{\circ} \mathrm{C}$. The original content of oil and dosage of $\mathrm{MgO}$ were $1.8 \mathrm{mg} / \mathrm{L}$ and $0.17 \mathrm{~g}$ respectively. Because of the limitation of experimental devices, removal rate could only be detected after $10 \mathrm{~min}$. The results showed that

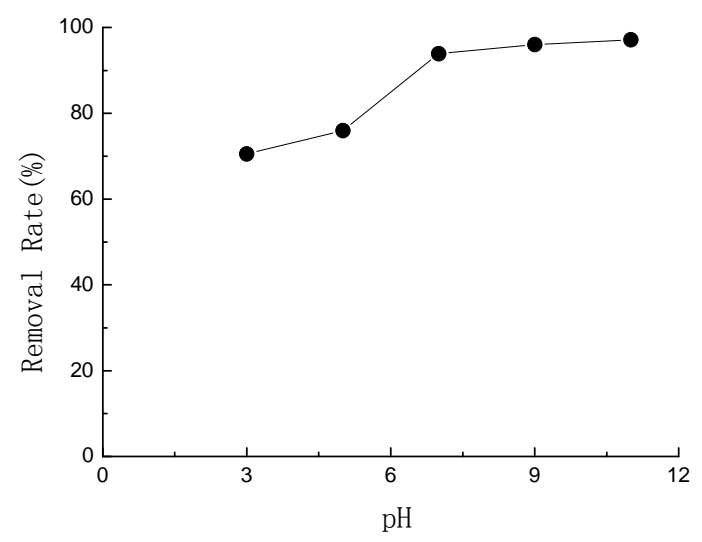

Figure 2. The influence of $\mathrm{pH}$ on oil degradation.

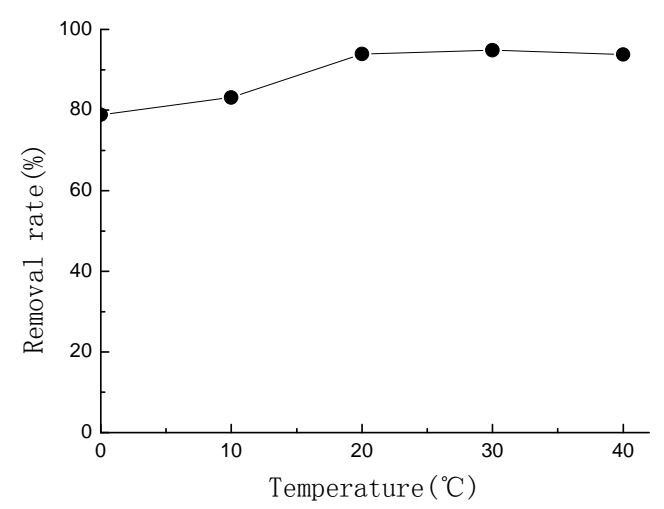

Figure 3. The influence of temperature on oil degradation. 
the removal rates of oil were greater than $90 \%$ during 60 min reaction time and nearly can't be influenced with the reaction time goes on, which indicated that the reaction of catalytic degradation was very fast and completed in a relative short time.

\subsection{The Influence of Light Irradiation on Oil Degradation}

On the condition of light irradiation, most nano-metal oxides are able to absorb electron-hole pairs the photon producing. Then electrons and holes are separated under the force of electric field and migrate to different location of nano-particles respectively, which are beneficial to photocatalytic reaction between nano-particles and organics. In order to study the relation between catalytic degradation property and light irradiation condition, we compare the removal properties of nano-MgO under the condition of indoor natural light and completely dark (Table 1). The results demonstrated that there was no significant different under the condition of light irradiation and dark, indicating nano-MgO was a non-photosensitive catalyst.

\subsection{GC/MS Analysis}

GC/MS is a useful method to learn the species and related information about organic compounds. Figure 5 showed the GC/MS graph of micro-polluted water of which oil content was $4.0 \mathrm{mg} / \mathrm{L}$. For this graph, the sequence of organic peaks indirectly represents the boiling point of organics. In other words, the boiling point determines the consequence of peaks. GC/MS analysis detected 72 peaks totally and each peak corresponded to relevant organic compound. Every peak was arranged on the graph in the light of boiling point, and the total area of peaks was $1.14 \times 108$. There were 61 kinds of organics in original micro-polluted water by GC/MS, mainly including 24 alkanes, 10 esters, 6 alkenes, 5 acids, 3 alcohols, 3 ethers, 2 amines and 9 others. Most of their molecular weight ranged from 100 to 300. Among those organics, alkanes were the most, which accounted for $39.34 \%$ of the total numbers of organics, and peak area of alkanes accounted for $64.76 \%$ of the total peak area, indicating that oil was a kind of mixture of hydrocarbons.

Figure 6 showed the GC/MS graph of oil polluted water after catalytic degradation of nano-MgO. The MgO

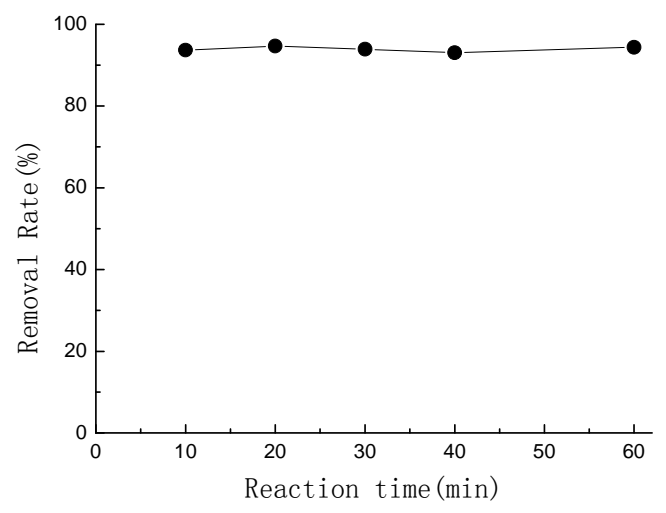

Figure 4. The influence of reaction time on oil degradation.

Table 1. The influence of light irradiation on oil degradation.

\begin{tabular}{cccc}
\hline \multirow{2}{*}{ condition } & \multicolumn{2}{c}{ Oil content, mg/L } & Removal rate, \% \\
\cline { 2 - 3 } & Before reaction & After reaction & \\
\hline $\begin{array}{c}\text { Indoor light } \\
\text { irradiation } \\
\text { Dark }\end{array}$ & 1.84 & 0.11 & 94.02 \\
\hline
\end{tabular}

Note: MgO dosage $0.17 \mathrm{~g}, \mathrm{pH}$, temperature $20^{\circ} \mathrm{C}$, reaction time $30 \mathrm{~min}$.

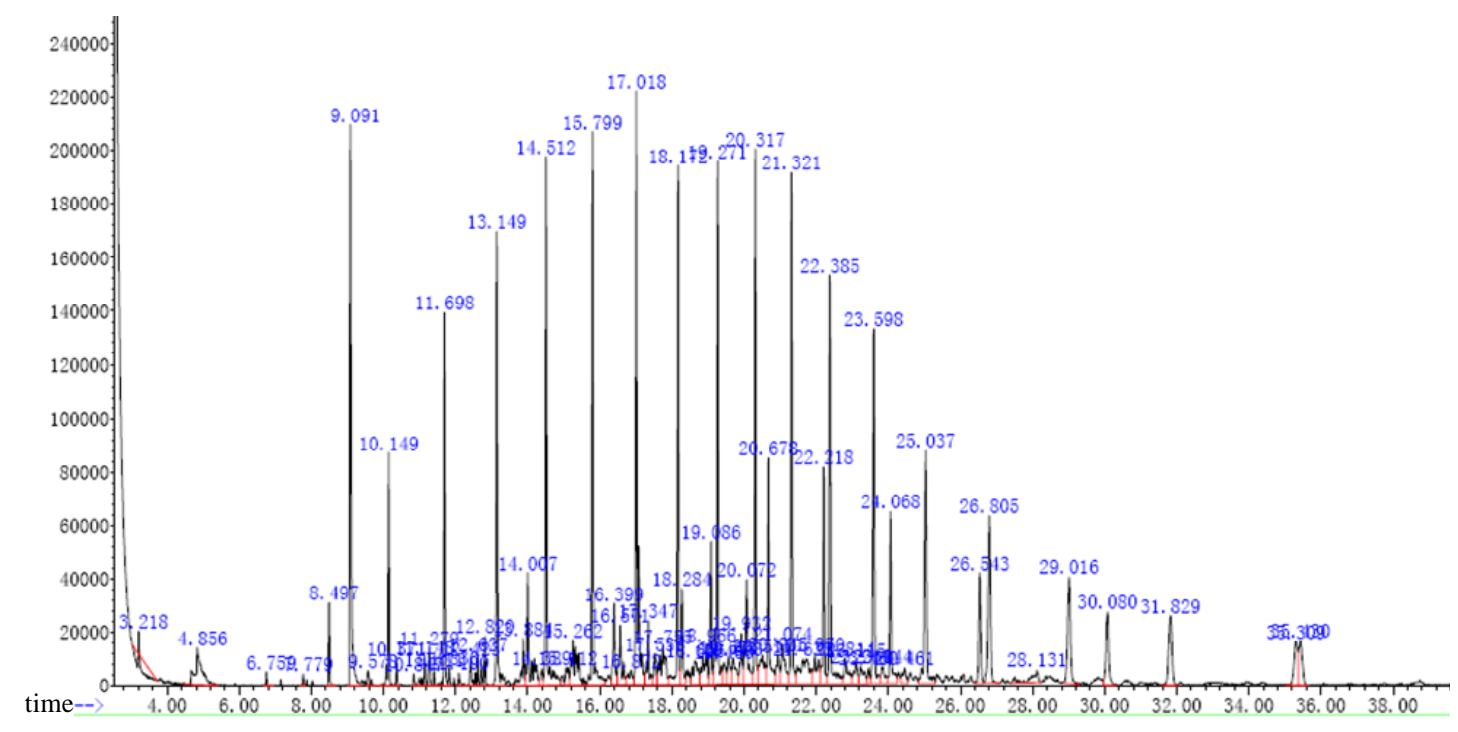

Figure 5. GC/MS graph of oil micro-polluted water. 


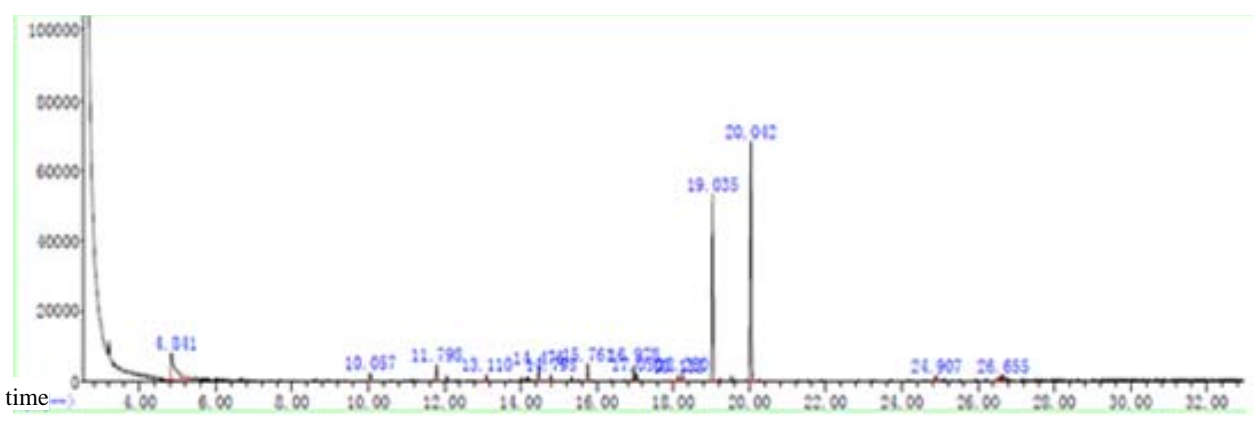

Figure 6. GC/MS graph after catalytic degradation of nano-MgO.

dosage was $0.40 \mathrm{~g}$ and reaction time was $30 \mathrm{~min}$. After the treatment of nano-MgO, the numbers of organic species in water reduced to 16 kinds. Comparing the organic composition of original water, there were 59 kinds of organics that existed in original water didn't be detected after treatment and only 2 species were remained. But another new 14 kinds of organics were detected in water after catalytic degradation of nano-MgO, including acids, amines and aldehydes. Generally speaking, the numbers of organic species reduced from original water's 61 to 16 species, by a reduction of 45 kinds. The numbers of peaks also reduced from 72 to 15 . The total area decreased from 1.14108 to 4.5106 , by a reduction of $96.05 \%$. It indicated that nano-MgO was able to catalytic degrade most of organics referring petroleum, and most of them were oxidized to $\mathrm{CO}_{2}$ and $\mathrm{H}_{2} \mathrm{O}$, and parts of organics were oxidized to small molecule intermediates.

\section{Conclusions}

Catalytic degradation effect of nano-MgO on the oil pollutants was associated with dosage of nano-MgO, $\mathrm{pH}$ and water temperature. When oil content was $1.8 \mathrm{mg} / \mathrm{L}, 0.17$ g nano-MgO was used and the removal rate of oil was 93.92\%. Furthermore, nano-Mgo was proved to be a non-photosensitive catalyst. Most of organics were oxidized to $\mathrm{CO}_{2}$ and $\mathrm{H}_{2} \mathrm{O}$, and parts of them were oxidized to small molecule intermediates. In conclusion, nano$\mathrm{MgO}$ has an excellent effect on the catalytic degradation of oil pollutants and can be applied in the treatment of oil wastewaters.

\section{REFERENCES}

[1] “Drinking Water Sanitary Standard,” GB5749-2006

[2] H. L. Yuan, "Microorganism Screening for Petroleum Degradation and Its Degrading Characteristics," China Environt Science, Vol. 23, No. 2, 2003, pp. 157-161.

[3] A. Snyder Shane, Westerhoff Paul, Yoon Yeomin, et al., "Pharmaceuticals, Personal Care Products, and Endocrine Disruptors in Water: Implications for the Water Industry,"Environmental Engineering Science, Vol. 20, No. 5, 2003, pp. 449-469.doi:10.1089/109287503768335931

[4] L. Huang, D. Q. Li, Y. J. Lin, et al., "Controllable Preparation of Nano-MgO and Investigation of Its Bactericidal Properties," Inorganic Bioche, Vol. 99, No. 5, 2005, pp. 986-993.doi:10.1016/j.jinorgbio.2004.12.022

[5] S. P. Decker, J. S. Klabunde, A. Khaleel, et al., "Catalyzed Destructive Adsorption of Environmental Toxins with Nanocrystalline Metal Oxides. Fluoro-, Chloro-, Bromocarbons, Sulfur, and Organophosophorus Compounds," Environmental Science Technology, Vol. 36, No.4, 2002, pp. 762-768.doi:10.1021/es010733z

[6] J. Araña, J. A. Herrera Melián, J. M. Doña Rodriguez, et al., " $\mathrm{TiO}_{2}$-photocatalysis as A Tertiary Treatment of Naturally Treated Wastewater," Catalysis Today, Vol. 76, No. 2-4, 2002, pp. 279-289. doi:10.1016/S0920-5861(02)00226-2 